УДК 616.61+616379-008.64:616.12-008.331.1

DOI: $10.26435 /$ UC.V0I4(37).596

\author{
Н.Ю. Кривонос, В.В. Коломиец
}

ГОО ВПО «Донецкий национальный медицинский университет имени М. Горького», Донецк

\title{
ДИАБЕТИЧЕСКАЯ НЕФРОПАТИЯ И АРТЕРИАЛЬНАЯ ГИПЕРТЕНЗИЯ: АКТУАЛЬНЫЕ ВОПРОСЫ НЕФРОПРОТЕКЦИИ
}

Сахарный диабет является одним из стремительно растущих заболеваний 21-го века с увеличением количества взрослых с этим диагнозом в три раза только за последние 20 лет. По данным Международной Федерации Диабета, у 463 миллионов взрослых людей в 2019 году был диагностирован сахарный диабет, еще десять лет назад, в 2010 году, глобальный прогноз по диабету на 2025 год составлял 438 миллионов, за девять лет этот прогноз уже превзошел 25 миллионов [18]. Количество взрослых с сахарным диабетом может увеличиться до 578 миллионов в 2030 году. Около 35-45\% случаев смерти от уремии приходится на больных СД. Считается, что у 10-40\% больных СД 2 типа развивается диабетическая нефропатия [18].

Одним из органов-мишеней при эссенциальной гипертензии (ЭГ) и СД 2 типа являются почки. Большинство случаев нефропатии обусловлено сахарным диабетом и артериальной гипертензией (АГ). Так, в исследовании MRFIT (Multiple Risk Factor Intervention Trial) указывается, что даже незначительное повышение артериального давления (АД) - более 130/85 мм рт.ст. - вызывает увеличение риска почечной патологии до 3-х раз [7]. При этом до сих пор не уточнен допустимый минимальный уровень АД для больных с ДН, при котором клубочковая фильтрация поддерживается на адекватном уровне.

В странах запада около 50\% больных, поступающих в отделения гемодиализа с диагнозом терминальная почечная недостаточность, являются пациенты с СД [4]. В России этот показатель составляет примерно 13\% от всех больных с заместительной почечной терапией (ТПН), что, видимо, связано с недостаточным количеством диализных мест, ранней сердечно-сосудистой смертностью и низкой продолжительностью жизни среди больных с СД [4].

Средства, необходимые для лечения осложнений со стороны почек, при СД составляют огромные суммы и являются достаточно весомыми даже для развитых капиталистических стран западного мира. В связи с неуклонным увеличением таких больных расходы, связанные с проведением диализа, продолжают только возрастать, что существенно сокращает финансирование других медицинских программ. Так, в США расходы, связанные с проведением заместительной почечной терапии (ЗПТ) больных с терминальной почечной недостаточностью (ТПН), оцениваются примерно в 40 млрд долларов ежегодно, что сопоставимо с годовыми бюджетами многих стран [28]. В перерасчете на одного человека стоимость лечения больного с ТПН в США составила 45 тыс. долларов в год.

По результатам исследования REIN (Ramipril Efficacy In Nephropathy), проводимого в Европейском, Союзе было установлено, что стоимость лечения одного больного с СД и ТПН доходила до 80 тыс. евро в год, а средний показатель составлял около 50 тыс. [14].

Диабетическую нефропатию (ДН) также иногда называют синдромом КиммельстилаУилсона в честь патологоанатомов Кимельстила и Уилсона, описавших в 1936 году своеобразное узелковое склеротическое поражение клубочков почек у 8 умерших больных, имевших в анамнезе СД 2-го типа, высокое АД и нефротический синдром. Основу морфологических изменений при данном синдроме составляют процессы, включающие узелковый и диффузный гломерулосклероз, утолщение базальной мембраны капилляров почечных клубочков, артерио- и артериолосклероз, а также канальцевоинтерстициальный фиброз. Принято считать, что ДН является достаточно поздним осложнением СД, так как выявляется у пациентов с большой продолжительностью диабета и фактически считается конечной стадией морфологических изменений в почках в виде узелкового гломерулосклероза, формирующегося в результате прогрессирования ДН [34]. ДН является основной причиной смерти у больных СД, превышая

( ) Н.Ю. Кривонос, В.В. Коломиец, 2020

(c) Университетская Клиника, 2020 
в 17 раз смертность, которая наблюдается в общей популяции [6].

Самые ранние изменения почечных структур обнаруживаются уже в первые месяцы дебюта СД, и они нарастают по мере длительности течения диабета. ДН, согласно классификации американской ассоциации 2010 года, делится на четыре степени иерархических клубочковых поражений с отдельной оценкой степени поражения интерстиция и клубочков [35]. При первом классе имеется утолщение базальной мембраны, при втором классе возникает так называемая мезенгимальная экспансия, уже при третьем классе наблюдается картина узелкого склероза (до 50\%), при четвертом - имеется выраженный гломерулосклероз более чем в 50\% клубочков. Классификационные схемы улучшают взаимодействие между морфологами и клиницистами и, соответсвенно, позволяют значительно повысить качество ведения таких пациентов [15].

Важную роль в понимании патогенеза развития ДН имеет открытие выдающегося нефролога из США В.M.Brennera феномена гиперфильтрации и внутриклубочковой гипертензии [12]. Пусковым механизмом, запускающим данный феномен, является гипергликемия, которая на начальных этапах вызывает функциональные, а позже и структурные изменения в почках, которые проявляются в результате накопления коллагена в области мезангиума нарушениями проницаемости базальной мембраны и, соответственно, микроальбуминурией (МАУ). Важным является понимание механизма истощения «функционального почечного резерва» (ФПР), а именно снижения клубочковой фильтрации (КФ) после белковой нагрузки. Согласно исследованиям, у больных с ЭГ в сочетании с СД 2 -го типа в $47,2 \%$ случаев выявлено снижение резерва фильтрации, в $48,7 \%$ отмечено истощение ФПР. Данное исследование демонстрирует, что при нарушении резервной способности почек они перестают адекватно увеличивать СКФ в ответ на стимуляцию. Исходя из этого можно сделать вывод, что все имеющиеся нефроны находятся в состоянии гиперфильтрации [5].

Фильтрация альбумина в клубочке сопровождается его повышенной проксимальной тубулярной реабсорбцией и ремоделированием канальцевого интерстиция с последующим фиброзированием. Повреждения канальцевого аппарата почек могут предшествовать повреждению клубочков, и более того, приводить к ним путем канальцево-клубочковой обратной связи [1]. Тубулярный аппарат почек претерпевает изменения на ранних этапах, опережающих клубочковые повреждения, и на поздних. Дисфунк- ция канальцев через тубуло-гломерулярный дисбаланс транслируется в повреждение клубочкового фильтра. Несмотря на это, значение канальцевых повреждений для развития нефропатии изучено недостаточно.

Большое влияние на прогрессирование ДН оказывает сверхвысокая активность локальной ренин-ангиотензин-альдостероновой системы (РАAC), к которой приводят и ЭГ и СД II типа. В ходе исследований было обнаружено, что локальная почечная концентрация ангиотензина II (AII) превышала его содержание в плазме более чем в 1000 раз. AII в почках, благодаря вазоконстрикторному, пролиферативному, прооксидантному действию, вызывает внутриклубочковую гипертензию [22]. Однако даже при значительной ишемии гломерулы долго сохранны, а тубулярный интерстиций атрофируется и фиброзируется (феномен „атубулярных нефронов”) [1].

В последнее время исследователи все больше внимания уделяют таким новым факторам риска в патогенезе ДН, как окислительный стресс и субклиническое воспаление. Повышенный уровень в моче 8-оксо-2'-дезоксигуанозина (8-оксо$\mathrm{dG)}$ является маркером окислительного стресса и может прогнозировать прогрессирование ДН у пациентов с СД 2 типа [17]. У пациентов с СД 2 типа имеется более высокий уровень противовоспалительных цитокинов и хемокинов (интерлейкина- 6 и 18, моноцитхемоаттрактант протеина- 1). Данные пациенты подвержены большему риску повреждения почек с развитием нефропатии [27]. Также установлено, что рецепторы пациентов с СД 2 типа более восприимчивы к фактору некроза опухоли- $\alpha$ (ФНО- $\alpha)$, что также связано с повреждением почек [16]. Пока, к сожалению, исследования, которые оценивали влияние антиоксидантов или противовоспалительных средств для снижения прогрессирования ДН, дали неутешительные результаты как в отношении их эффективности, так и безопасности [33]. Имеется также расовая предрасположенность к развитию ДН. Так, например, у афроамериканцев и индейцев племени Пима ДН встречается чаще, чем у кавказцев [23].

Диагностика диабетической нефропатии основана на экскреции альбумина с мочой, так как именно его повышенный уровень является первым признаком ДН. Если экскреция альбумина составляет 30-300 мг/сут, это умеренная МАУ; у пациентов, у которых уровень альбуминурии составляет >300 мг/сут (макроальбумиурия), особенно высок риск возникновения сниженной почечной функции. Согласно последним рекомендациям, выпущенным Американской диабетической ассоциацией (ADA), 
наличие альбумина в моче должно измеряться хотя бы ежегодно у всех пациентов с СД 2 типа. МАУ меняется в динамике, и поэтому, прежде чем поставить диагноз нефропатии, мы должны увидеть в двух или более образцах мочи, собранных в течение 3-6 месяцев, увеличение экскреции альбумина [10]. МАУ часто сопровождает такие факторы риска, как АГ, ожирение, дислипидемия, гиперурикемия. Считается, что МАУ может иметь место у 40\% больных АГ. Необходимо иметь в виду, что СД может быть диагностирован спустя много лет после его начала и очень часто больные имеют один или несколько сопутствующих факторов риска, названных выше, особенно это касается АГ, которая усиливает повреждение почек и прогрессирование ТПН [9]. Принято считать, что АГ связана с ДН как в качестве причины ДН, так и вследствие самой ДН [36]. Хороший контроль АД - необходимая цель в профилактике ДН, а также замедлении прогрессирования ДН у людей с СД 2 типа [36]. Контроль АГ у больных ДН не только уменьшает прогрессирование ДН, но также имеет важное значение для снижения распространенности сердечно-сосудистых заболеваний. Исследования, которые проводились на протяжении последних лет, выявили необходимость контроля АД в профилактике сердечно-сосудистых заболеваний [31]. Кроме того, первичная профилактика и вторичное лечение ДН также имеют серьезные сердечно-сосудистые преимущества: как показали многие исследования, имеется тесная связь между ухудшением при ДН и большим количеством сердечно-сосудистых событий [24]. У пациентов с СД и АГ важна адекватная коррекция АД. Например, 8-й консенсус группы специалистов из США по ведению пациентов с повышенным уровнем АД (JNC 8) рекомендовал контролировать АД <140/90 для всех больных, включая пациентов с хронической болезнью почек, и <150/90 для тех пациентов, чей возраст превышает 60 лет [19]. Однако следует при этом уточнить и допустимый уровень систолического и диастолического АД, способный поддерживать необходимую интенсивность гломерулярной фильтрации. В качестве препаратов первой линии у пациентов с СД 2 типа рассматриваются ингибиторы ангиотензинпревращающего фермента (АПФ), так как они имеют доказанный антипротеинурический эффект [32]. Кроме препаратов группы ингибиторов АПФ, доказанным антипротеинурическим эффектом у больных ДН обладает представитель недигидропиридиновых антагонистов кальция амлодипин [26]. Нефропротекторный эффект амлодипина связан не только со снижением АД, в том числе и снижением внутриклубочковой гипертензии, уменьшением процессов фиброзирования, но и влиянием на оксидативный стресс канальцев нефрона [21]. В отличие от ингибиторов АПФ и амлодипина, селективные бета-блокаторы (ББ) не рассматриваются как препараты первого выбора для лечения ДН, так как, несмотря на многочисленные исследования, подтверждающие их положительный эффект у данной категории больных, у врачей сложилось ошибочное мнение об их отрицательном влиянии на толерантность к инсулину, хотя это прежде всего относится к неселективным ББ. В настоящее время хорошо себя зарекомендовали такие селективные ББ, как небиволол и бисопролол. Отдельно хочется выделить небиволол, который обладает еще и вазодилатирующим эффектом за счет способности стимулировать систему L-аргининNO и, соответственно, образование эндотелиального NO, который влияет не только на афферентную, но и на эфферентную артериолу почечной гломерулы, что обеспечивает его высокий нефропротекторный эффект [2]. Возвращаясь к инсулинорезистентности ББ, следует отметить, что в результате проведенных исследований появились данные, что небиволол, напротив, способствует ее повышению [29]. Роль дисбаланса вегетативной регуляции с адренергической активацией в развитии и прогрессировании ДН у больных ЭГ в настоящее время также недостаточно изучена с учетом вклада адренергической активации в состояние гломерулярного и перитубулярного кровотока, обусловливающего функцию клубочкового и канальцевого аппарата почек.

Одним из важнейших метаболических факторов, приводящих к прогрессированию ДН, является гиперлипидемия и дислипидемия. Принято считать, что дислипидемия при СД 2 типа - это состояние, которое включает гипертриглицеридемию, низкий уровень липопротеинов высокой плотности (ЛПВП) и увеличение мелких (ЛПНП) и очень мелких липопротеинов низкой (ЛПОНП) плотности. В настоящее время появляется все больше данных, указывающих на способность статинов снижать уровень альбуминурии. По данным ряда исследователей, это происходит за счет снижения трансформирующего фактора роста $\beta$ (ТФР- $\beta$ ), что приводит к уменьшению процессов воспаления и фиброзирования в почках [11]. При этом ТФР- $\beta$ определяется как самый значимый медиатор накопления компонентов мезангиального внеклеточного матрикса и развития почечной гипертрофии, а основным медиатором прогрессирования диабетической альбуминурии признается подоцитвыделяемый сосудистый эндотелиальный фактор роста (VEGF) - фактор проницаемости и 
ангиогенеза, экспрессия которого существенно увеличена при ДН [13].

Кроме этого, статины обладают дополнительными «холестерин-независимыми» нефропротекторными свойствами, такими как способность повышать содержание оксида азота (NO), и антиоксидантное свойство [25]. Несмотря на противоречивые данные о неблагоприятном воздействии статинов на показатели углеводного обмена, авторитетные международные организации ADA и Европейская ассоциация по изучению диабета (EASD) в своих последних рекомендациях однозначно рекомендуют их больным с СД 2 типа, учитывая возраст пациента и наличие документально подтвержденного риска атеросклеротических сердечно-сосудистых заболеваний (АССЗ). Вопрос о дозах статинов для больных с ДН остается недостаточно изученным.

Учитывая, что все вышеуказанные препараты так или иначе воздействуют на эндотелий сосудов, перспективным будет считаться использование в качестве нефропротектора при ДН такого препарата, как L-аргинин, который улучшает доступность эндогенного NO за счет стимуляции NO синтетазы и тем самым устраняет парадоксальную вазоконстрикцию в артериолах почечных гломерул [3]. Согласно проведенным экспериментальным исследованиям, L-аргинин снижал как систолическое, так и диастолическое давление, причем систолическое в большей степени. Также отмечалось снижение уровня инсулинорезистентности, гиперлипидемии и дислипидемии [20]. В дальнейших исследованиях целесообразно расширить представления о значении недостаточного синтеза NO в нарушениях функционального состояния почек при СД 2 типа и ЭГ, а также возможности коррекции нарушений функции не только клубочкового, но и канальцевого аппарата почек, роль которого в развитии нефропатии вообще недооценивается.

Требуется подтверждение благоприятного нефропротекторного воздействия L-аргинина в клинических условиях.

Лечение ДН является тяжелой, но выполнимой задачей, направленной на медикаментозную коррекцию нарушений ренин-ангиотензинальдостероновой, симпато-адреналовой систем, гиперлипидемии и дислипидемии, эндотелийзависимой вазодилятации для оптимизации гломерулярного и перитубулярного кровотока и функции клубочкового и канальцевого аппарата почек. Несомненно, добиться обратного развитие морфологических изменений в почках можно только в результате длительного и комплексного медикаментозного лечения.

\section{Н.Ю. Кривонос, В.В. Коломиец}

ГОО ВПО «Донецкий национальный медицинский университет имени М. Горького», Донецк

\section{ДИАБЕТИЧЕСКАЯ НЕФРОПАТИЯ И АРТЕРИАЛЬНАЯ ГИПЕРТЕНЗИЯ: АКТУАЛЬНЫЕ ВОПРОСЫ НЕФРОПРОТЕКЦИИ}

В обзоре представлены последние статистические данные распространенности сахарного диабета с указанием экономического бремени, связанного с покрытием расходов на заместительную почечную терапию, вызванную диабетической нефропатией. Представлены механизмы развития и прогрессирования диабетической нефропатии, в том числе у пациентов с артериальной гипертензией. В обзоре рассматривается влияние на прогрессирование диабетической нефропатии таких факторов риска, как артериальная гипертензия, дислипидемия, окислительный стресс и субклиническое воспаление, а также системы L-аргинин-NO. Указаны критерии диа- гностики диабетической нефропатии на ранней стадии, основанные на экскреции альбумина с мочой. Подробно рассматриваются группы препаратов, применяемые в настоящее время с целью коррекции артериальной гипертензий, гиперлипидемии и дислипидемии у больных, с учетом международных рекомендаций. Приводятся данные о перспективном направлении в нефропротекции, а именно - воздействии на эндотелий сосудов артериол гломерул с помощью L-аргинина.

Ключевые слова: диабетическая нефропатия, артериальная гипертензия, нефпропротекция. 


\section{N.Yu. Krivonos, V.V. Kolomiets}

\section{SEI HPE «M. Gorky Donetsk National Medical University», Donetsk}

\section{DIABETIC NEPHROPATHY AND ARTERIAL HYPERTENSION: TOPICAL ISSUES OF NEPHROPROTECTION}

The review presents the latest statistics on the prevalence of diabetes mellitus, indicating the economic burden associated with the cost of renal replacement therapy caused by diabetic nephropathy. The mechanisms of development and progression of diabetic nephropathy, including in patients with arterial hypertension, are presented. The review examines the influence of risk factors such as arterial hypertension, dyslipidemia, oxidative stress and subclinical inflammation, as well as the L-arginine-NO system, on the progression of diabetic nephropathy. Criteria for the diagnosis of diabetic neph- ropathy at an early stage based on urinary albumin excretion are indicated. The groups of drugs currently used to correct arterial hypertension, hyperlipidemia and dyslipidemia in patients with diabetic nephropathy are discussed in detail with a discussion of their properties and benefits based on the latest international recommendations. Data on a promising direction in nephroprotection, namely, the effect on the vascular endothelium of glomerul arterioles using L-arginine are presented.

Key words: diabetic nephropathy, arterial hypertension, nephroprotection.

\section{ЛИТЕРАТУРА}

1. Коломиец В.В., Кривонос Н.Ю. 2018. Канальцевый транспорт в почках больных эссенциальной гипертензией в сочетании с сахарным диабетом II типа. Научные ведомости Белгородского государственного университета. Медицина Фармация. 41 (2):254-268.

2. Кривонос Н.Ю. Коломиец В.В. 2019. Оценка состояния симпато-адреналовой системы у больных эссенциальной гипертензией в сочетании с сахарным диабетом 2 типа с наличием нефропатии при лечении небивололом. Научные ведомости Белгородского государственного университета. Медицина Фармация. 42 (2):151158.

3. Кушниренко С.В. Сосудистые препараты в нефрологии . Почки. 2013; 2 (4): 47-50.

4. Надеева Р.А.,Сагитова О.Н. Клинические рекомендации по лечению диабетической нефропатии. Архивъ терапевтической медицины. 2015; 5 (25): 3-8.

5. Скалій Н.М. Медикаментозна корекція діабетичної нефропатії на стадії гіперфшльтрації. Нирки. 2016; 1(15): 71-73.

6. Тареева И.Е. Механизмы прогрессирования гломерулонефрита. Терапевтический архив. 1996; 6: 5-10.

7. Чукаева И.И., Спирякина Я.Г., Грибанов В.П. Нефропротекция у пациентов с артериальной гипертензией - возможности полнодозовых фиксированных комбинаций. Кардиология. Эндокринология РМЖ. 2014; 23: 1699-1703.

8. Шестакова М.В. Диабетическая нефропатия: перспективы лечения. Терапевтический архив. 2002; 74 (6): 2427.

9. Шестакова М.В., Шамхалова М.Ш., Ярек-Мартынова И.Я. и пр. Сахарный диабет и хроническая болезнь почек: достижения, нерешенные проблемы и перспективы лечения. Сахарный диабет. 2011; 1:81-81.

10. American Diabetes Association. Standards of medicalcare in diabetes 2019. Diabetes Care 2019. 38(Suppl 1):S1S94.

11. Athyros V.G., Kakafika A. I., Karagiannis A.? et al. Do we need to consider inflammatory markers when we treat atherosclerotic disease? Atherosclerosis. 2008; 200 (6): 1-12.

12. Brenner B. M. The hyperfiltration theory: A paradigm shift in nephrology. Kidney Int. 1996; (49)6: 1774-1777.

13. Chen S., Jim B., Ziyadeh F.N. Diabetic nephropathy and transforming growth factor-beta: transforming our view of glomerulosclerosis and fibrosis build-up. Semin. Nephrol. 2003; (23)6: 532-543.

14. Costa-Scharplatz M., van Asselt A.D., Bachmann L.M. et al. Costeffectiveness of pharma cogenetic testing to predict treatment response to angiotensin-converting enzyme inhibitor. Pharmacogenet Genomics. 2007; 17: 359-

\section{REFERENCES}

1. Kolomiets V.V., Krivonos N.Yu. 2018. Kanal'tsevyi transport v pochkakh bol'nykh essentsial'noi gipertenziei v sochetanii s sakharnym diabetom 2 tipa. Nauchnye vedomosti Belgorodskogo gosudarstvennogo universiteta. Meditsina Farmatsiya. [Tubular transport in kidneys of the patients with essential hypertension in combination with diabetes mellitus type II] 41 (2):254-268 (in Russian).

2. Krivonos N.Yu. Kolomiets V.V. 2019. Otsenka sostoyaniya simpato-adrenalovoi sistemy u bol'nykh essentsial'noi gipertenziei v sochetanii s sakharnym diabetom 2 tipa s nalichiem nefropatii pri lechenii nebivololom. Nauchnye vedomosti Belgorodskogo gosudarstvennogo universiteta. Meditsina Farmatsiya. [Assessment of the state of the sympathoadrenal system in patients with essential hypertension combined with type 2 diabetes mellitus with nephropathy treated with nebivolol] 42 (2):151-158 (in Russian).

3. Kushnirenko S.V. Sosudistye preparaty v nefrologii [Vascular drugs in nephrology] Pochki. 2013; 2 (4): 47-50. (in Russian).

4. Nadeeva R.A.,Sagitova O.N. Klinicheskie rekomendatsii po lecheniyu diabeticheskoi nefropatii. Arkhiv" terapevticheskoi meditsiny [Clinical practice guidelines for the treatment of diabetic nephropathy] 2015; 5 (25): 3-8 (in Russian).

5. Skalii N.M. Medikamentozna korektsiya diabetichnoï nefropatiï na stadiï giperfil'tratsiï [Drug correction of diabetic nephropathy at the stage of hyperfiltration] Nirki. 2016; 1(15): 71-73 (in Ukrainian).

6. Tareeva I.E. Mekhanizmy progressirovani ya glomerulonefrita [Mechanisms of progression of glomerulonephritis] Terapevticheskii arkhiv. 1996; 6: 5-10 8 (in Russian).

7. Chukaeva I.I., Spiryakina Ya.G., Gribanov V.P. Nefroprotektsiya u patsientov s arterial'noi gipertenziei - vozmozhnosti polnodozovykh fiksirovannykh kombinatsii [Nephroprotection in patients with arterial hypertension - the possibilities of full-dose fixed combinations] Kardiologiya. Endokrinologiya RMZh. 2014; 23: 1699-1703 (in Russian).

8. Shestakova M.V. Diabeticheskaya nefropatiya: perspektivy lecheniya [Diabetic Nephropathy]: Treatment Prospects Terapevticheskii arkhiv. 2002; 74 (6): 24-27 (in Russian).

9. Shestakova M.V., Shamkhalova M.Sh., Yarek-Martynova I.Ya. i pr. Sakharnyi diabet i khronicheskaya bolezn' pochek: dostizheniya, nereshennye problemy i perspektivy lecheniya [Diabetes Mellitus and Chronic Kidney Disease: Achievements, Unresolved Issues and Treatment Prospects] Sakharnyi diabet. 2011; 1:81-81 (in Russian).

10. American Diabetes Association. Standards of medicalcare in diabetes 2019. Diabetes Care 2019. 38(Suppl 1):S1S94 
368.

15. Glassock RJ: Reclassification of lupus glomerulonephritis: Back to the future. J AmSoc Nephrol. 2004;15: 501503.

16. Gohda T, Niewczas MA, Ficociello LH. et al. Circulating TNF receptors 1 and 2 predict stage 3 CKD in type 1 diabetes. J Am Soc Nephrol. 2012; 23:516-524.

17. Hinokio Y, Suzuki S, Hirai M., et al. Urinary excretion of 8-oxo-7, 8-dihydro-2'-deoxyguanosine as a predictor of the development of diabetic nephropathy. Diabetologia. 2002; 45:877-882.

18. International Diabetes Federation Diabetes Atlas Update 2019. http://www.idf.org/diabetesatlas/9e/Update2019.

19. James PA, Oparil S, Carter BL et al. 2014 evidence-based guideline for the management of high blood pressure in adults: report from the panel members appointed to the Eighth Joint National Committee (JNC 8). JAMA 2014; 311: 507-520

20. Lucilla D. Monti et al. L-arginine Enriched Biscuits Improve Endothelial Function and Glucose Metabolism: A Pilot Study in Healthy Subjects and a Cross-Over Study in Subjects With Impaired Glucose Tolerance and Metabolic Syndrome. Metabolism. 2013; 62 (2):255-64.

21. Nakamura T., Sato E., Fujiwara N. et al. (2011) Calcium channel blocker inhibition of AGE and RAGE axis limits renal injury in nondiabetic patients with stage I or II chronic kidney disease. Clin. Cardiol. 34(6): 372-377.

22. Navar L.G., Harrison-Bernard L.M., Imig J.D. et al. Intrarenal angiotensin II generation and renal effects of ATI receptor blockade. J. Am. Soc.Nephrol. 1999; 10: 266-272.

23. Nelson RG, Knowler WC, Pettitt DJ., et al. Diabetic kidney disease in Pima Indians. DiabetesCare.1993; 16:335-341.

24. Ninomiya T, Perkovic V, de Galan BE et al. Albuminuria and kidney function independently predict cardiovascular and renal outcomes in diabetes. J Am Soc Nephrol. 2009; 20: 1813-1821.

25. Nikolic D., Banach M., Nikfar S., et al. Lipid and Blood Pressure Meta-Analysis Collaboration Group. A metaanalysis of the role of statins on renal outcomes in patients with chronic kidney disease. Is the duration oftherapy important? Int I Cardiol. 2013; 168(6): 5437-5447.

26. Nosadini R., Tonolo G. Relationship between blood glucose control, pathogenesis and progression of diabetic nephropathy. J. Am. Soc. Nephrol. 2004; 1: 1-5.

27. Persson F, Rossing P, Hovind P., et al. Endothelial dysfunction and inflammation predict development of diabetic nephropathy in the Irbesartan in Patients with Type 2 Diabetes and Microalbuminuria (IRMA 2) study. Scand IClin Lab Invest. 2008; 68:731-738.

28. Postma M.J., de Zeeuw D. The economic benefits of preventing end-stage renal disease in patients with type 2 diabetes mellitus . Nephrol. Dial. Transplant. 2009; 24: 2975-2298.

29. Poirier L, Cléroux J, Nadeau A. et al. Effects of nebivolol and atenolol on insulin sensitivity and haemodynamics in hypertensive patients. J Hypertens.Aug. 200119 (8):142935.

30. Practice Committee. Standards of medical care in diabetes - 2015: summary of revisions. Diabetes Care. 2015; 38:4.

31. Rosendorff C, Lackland DT, Allison M et al. Treatment of hypertension in patients with coronary artery disease: a scientific statement from the american heart association, american college of cardiology, and american society of hypertension. Circulation 2015; 131: e435-e470.

32. Ruggenenti P, Fassi A, Ilieva AP. et al. Preventing microalbuminuria in type 2 diabetes. N Engl J Med. 2004; 351:1941-1951.

33. Satko SG, Langefeld CD, Daeihagh P. et al. Nephropathy in siblings of African Americans with overt type 2 diabetic nephropathy. Am JKidney Dis. 2002; 40:489-494.

34. Tapp RJ, Shaw JE, Zimmet PZ. RC. et al. Albuminuria is evident in the early stages of diabetes onset: results from the Australian Diabetes, Obesity, and Lifestyle Study (AusDiab). Am J Kidney Dis. 2004; 44:792-798.

35. Tervaert T.W., Mooyaart A.L., Amann K. et al. On behalf
11. Athyros V.G., Kakafika A. I., Karagiannis A.? et al. Do we need to consider inflammatory markers when we treat atherosclerotic disease? Atherosclerosis. 2008; 200 (6): 1-12.

12. Brenner B. M. The hyperfiltration theory: A paradigm shift in nephrology. Kidney Int. 1996; (49)6: 1774-1777.

13. Chen S., Jim B., Ziyadeh F.N. Diabetic nephropathy and transforming growth factor-beta: transforming our view of glomerulosclerosis and fibrosis build-up. Semin. Nephrol. 2003; (23)6: 532-543.

14. Costa-Scharplatz M., van Asselt A.D., Bachmann L.M. et al. Costeffectiveness of pharma cogenetic testing to predict treatment response to angiotensin-converting enzyme inhibitor. Pharmacogenet Genomics. 2007; 17: 359368.

15. Glassock RJ: Reclassification of lupus glomerulonephritis: Back to the future. J AmSoc Nephrol. 2004;15: 501503.

16. Gohda T, Niewczas MA, Ficociello LH. et al. Circulating TNF receptors 1 and 2 predict stage 3 CKD in type 1 diabetes. J Am Soc Nephrol. 2012; 23:516-524.

17. Hinokio Y, Suzuki S, Hirai M., et al. Urinary excretion of 8-oxo-7, 8-dihydro-2'-deoxyguanosine as a predictor of the development of diabetic nephropathy. Diabetologia. 2002; 45:877-882.

18. International Diabetes Federation Diabetes Atlas Update 2019. http://www.idf.org/diabetesatlas/9e/Update2019.

19. James PA, Oparil S, Carter BL et al. 2014 evidence-based guideline for the management of high blood pressure in adults: report from the panel members appointed to the Eighth Joint National Committee (JNC 8). JAMA 2014; 311 : 507-520

20. Lucilla D. Monti et al. L-arginine Enriched Biscuits Improve Endothelial Function and Glucose Metabolism: A Pilot Study in Healthy Subjects and a Cross-Over Study in Subjects With Impaired Glucose Tolerance and Metabolic Syndrome. Metabolism. 2013; 62 (2):255-64.

21. Nakamura T., Sato E., Fujiwara N. et al. (2011) Calcium channel blocker inhibition of AGE and RAGE axis limits renal injury in nondiabetic patients with stage I or II chronic kidney disease. Clin. Cardiol. 34(6): 372-377.

22. Navar L.G., Harrison-Bernard L.M., Imig J.D. et al. Intrarenal angiotensin II generation and renal effects of ATI receptor blockade. J. Am. Soc.Nephrol. 1999; 10: 266-272.

23. Nelson RG, Knowler WC, Pettitt DI., et al. Diabetic kidney disease in Pima Indians. DiabetesCare.1993; 16:335-341.

24. Ninomiya T, Perkovic V, de Galan BE et al. Albuminuria and kidney function independently predict cardiovascular and renal outcomes in diabetes. J Am Soc Nephrol. 2009; 20: 1813-1821.

25. Nikolic D., Banach M., Nikfar S., et al. Lipid and Blood Pressure Meta-Analysis Collaboration Group. A metaanalysis of the role of statins on renal outcomes in patients with chronic kidney disease. Is the duration oftherapy important? Int J Cardiol. 2013; 168(6): 5437-5447.

26. Nosadini R., Tonolo G. Relationship between blood glucose control, pathogenesis and progression of diabetic nephropathy. J. Am. Soc. Nephrol. 2004; 1: 1-5.

27. Persson F, Rossing P, Hovind P., et al. Endothelial dysfunction and inflammation predict development of diabetic nephropathy in the Irbesartan in Patients with Type 2 Diabetes and Microalbuminuria (IRMA 2) study. Scand JClin Lab Invest. 2008; 68:731-738.

28. Postma M.J., de Zeeuw D. The economic benefits of preventing end-stage renal disease in patients with type 2 diabetes mellitus . Nephrol. Dial. Transplant. 2009; 24: 2975-2298.

29. Poirier L, Cléroux J, Nadeau A. et al. Effects of nebivolol and atenolol on insulin sensitivity and haemodynamics in hypertensive patients. J Hypertens.Aug. 200119 (8):142935 .

30. Practice Committee. Standards of medical care in diabetes - 2015: summary of revisions. Diabetes Care. 2015; 38:4.

31. Rosendorff C, Lackland DT, Allison M et al. Treatment of hypertension in patients with coronary artery disease: a scientific statement from the american heart association, 
of the Renal Pathology Society. Pathologic Classification of Diabetic Nephropathy. J Am Soc Nephrol. 2010; 21 (4): 556-563.

36. Van Buren PN, Toto R. Hypertension in diabetic nephropathy: epidemiology, mechanisms, and management. Adv Chronic Kidney Dis. 2011; 18: 28-41. american college of cardiology, and american society of hypertension. Circulation 2015; 131: e435-e470.

32. Ruggenenti P, Fassi A, Ilieva AP. et al. Preventing microalbuminuria in type 2 diabetes. N Engl J Med. 2004; 351:1941-1951.

33. Satko SG, Langefeld CD, Daeihagh P. et al. Nephropathy in siblings of African Americans with overt type 2 diabetic nephropathy. Am JKidney Dis. 2002; 40:489-494.

34. Tapp RJ, Shaw JE, Zimmet PZ. RC. et al. Albuminuria is evident in the early stages of diabetes onset: results from the Australian Diabetes, Obesity, and Lifestyle Study (AusDiab). Am J Kidney Dis. 2004; 44:792-798.

35. Tervaert T.W., Mooyaart A.L., Amann K. et al. On behalf of the Renal Pathology Society. Pathologic Classification of Diabetic Nephropathy. J Am Soc Nephrol. 2010; 21 (4): 556-563.

36. Van Buren PN, Toto R. Hypertension in diabetic nephropathy: epidemiology, mechanisms, and management. Adv Chronic Kidney Dis. 2011; 18: 28-41. 